\title{
Misframed ubiquitin and impaired protein quality control: an early event in Alzheimer's disease
}

\author{
Romina J. Gentier and Fred W. van Leeuwen* \\ Department of Neuroscience, Faculty of Health, Medicine and Life Sciences, Maastricht University, Maastricht, Netherlands
}

\section{OPEN ACCESS}

Edited by:

Rameshwar K. Sharma,

Salus University, USA

Reviewed by:

Nicolas Sergeant,

Inserm UMR S1172, France

Giovanni Piccoli,

Università Vita-Salute San Raffaele,

Italy

${ }^{*}$ Correspondence:

Fred W. van Leeuwen,

Department of Neuroscience,

Faculty of Health, Medicine and Life

Sciences, Maastricht University,

Universiteitssingel 50,

6229 ER Maastricht, Netherlands

f.vanleeuwen@maastrichtuniversity.nl

Received: 22 June 2015

Accepted: 18 August 2015

Published: 02 September 2015

Citation:

Gentier RJ and van Leeuwen FW

(2015) Misframed ubiquitin and impaired protein quality control: an early event in Alzheimer's disease.

Front. Mol. Neurosci. 8:47. doi: 10.3389/fnmol.2015.00047
Amyloid $\beta(A \beta)$ plaque formation is a prominent cellular hallmark of Alzheimer's disease (AD). To date, immunization trials in $A D$ patients have not been effective in terms of curing or ameliorating dementia. In addition, $\gamma$-secretase inhibitor strategies await clinical improvements in AD. These approaches were based upon the idea that autosomal dominant mutations in amyloid precursor protein (APP) and Presenilin 1 (PS1) genes are predictive for treatment of all $A D$ patients. However most $A D$ patients are of the sporadic form which partly explains the failures to treat this multifactorial disease. The major risk factor for developing sporadic $A D(S A D)$ is aging whereas the Apolipoprotein $\mathrm{E}$ polymorphism ( $\varepsilon 4$ variant) is the most prominent genetic risk factor. Other mediumrisk factors such as triggering receptor expressed on myeloid cells 2 (TREM2) and nine low risk factors from Genome Wide Association Studies (GWAS) were associated with AD. Recently, pooled GWAS studies identified protein ubiquitination as one of the key modulators of $A D$. In addition, a brain site specific strategy was used to compare the proteomes of AD patients by an Ingenuity Pathway Analysis. This strategy revealed numerous proteins that strongly interact with ubiquitin (UBB) signaling, and pointing to a dysfunctional ubiquitin proteasome system (UPS) as a causal factor in AD. We reported that DNA-RNA sequence differences in several genes including ubiquitin do occur in $A D$, the resulting misframed protein of which accumulates in the neurofibrillary tangles (NFTs). This suggests again a functional link between neurodegeneration of the AD type and loss of protein quality control by the UPS. Progress in this field is discussed and modulating the activity of the UPS opens an attractive avenue of research towards

\footnotetext{
Abbreviations: $\mathrm{A} \beta$, amyloid $\beta$; AICD, APP intracellular domain; ADAM10, A Disintegrin and metalloproteinase domaincontaining protein 10; AD, Alzheimer's disease; APP, amyloid precursor protein; APPs, soluble N-terminal part of APP; APP-CTF, C-terminal part of APP; DS, Down syndrome; DUB, deubiquitinating enzyme; EOAD, early-onset AD; ERAD, endoplasmic reticulum associated degradation; FAD, familial Alzheimer's disease; FC, fear conditioning; FENIB, familial encephalopathy with neuroserpin inclusion bodies; G, glycine; GWAS, genome wide association studies; HD, Huntington's disease; HECT, homologous to E6-associated protein C-terminus; HSP, heat-shock proteins; JAMM, JAB1/MPN/Mov34 metalloenzyme; LOAD, late-onset AD; K, lysine; MCI, mild cognitive impairment; MJD, Machado-Joseph Disease protein domain protease; MWM, Morris water maze; NFT, neurofibrillary tangle; NMD, non-sense mediated RNA decay; NP, neuritic plaque; NT, neuropil thread; NTS, nucleus of the solitary tract; OTU, ovarian tumor proteases; PBN, parabrachial nucleus; PD, Parkinson's disease; PHF, paired helical filament; PS1, presenilin 1; PS2, presenilin 2; RDD, RNA-DNA differences; RING, really interesting new gene; RPT, regulatory particle triple; SAD, sporadic Alzheimer's disease; tg, transgenic; TREM2, triggering receptor expressed on myeloid cells 2 ; $\mathrm{UBB}$, ubiquitin; $\mathrm{UBB}^{+1}$, ubiquitin $\mathrm{B}^{+1}$; $\mathrm{UCH}$, ubiquitin C-terminal hydrolase; UFD, ubiquitin fusion degradation; UPS, ubiquitin proteasome system; USP, ubiquitin specific proteases.
} 
slowing down the development of $\mathrm{AD}$ and ameliorating its effects by discovering prime targets for AD therapeutics.

Keywords: frameshift mutation, mRNA surveillance, molecular misreading, proteasome, amyloid precursor protein, tau, neurodegeneration

Alzheimer's disease (AD) is a progressive multifactorial neurological disease and the most prevalent form of dementia, accounting for $60-80 \%$ of all cases of dementia (Barnes and Yaffe, 2011). Many reviews have been written about this complex neurodegenerative disease e.g., (Selkoe et al., 2012). The sporadic (SAD) and familial (FAD) forms are the two major types of $\mathrm{AD}$ which differ in the age and cause of onset (Figure 1). $\mathrm{SAD}$ is heterogeneous with risk factors for developing $\mathrm{AD}$ including aging, cognitive inactivity, depression, oxidative stress, brain injury, epigenetic factors and mild cognitive impairment (MCI). Cardiovascular factors (cholesterol status, diabetes, midlife hypertension, obesity, physical inactivy and smoking) as well as genetic risk or dubbed timing factors (apolipoprotein E4 polymorphism; Apoe4) are also associated with the development of SAD (Querfurth and LaFerla, 2010; Alzheimer's Association, 2012). Other medium-risk factors such as a rare missense mutation ( $\mathrm{R} 47 \mathrm{H}$ subsitiution) in the gene encoding the triggering receptor expressed on myeloid cells 2 (TREM2), which has in a normal situation an antiinflammatory role in the brain, lead to an increased risk for $\mathrm{AD}$ through aberrant inflammatory processes (Jonsson et al., 2013). An additional nine low risk factors detected via Genome Wide Association Studies (GWAS) were reported to contribute as well to AD (Holton et al., 2013). Genetic factors
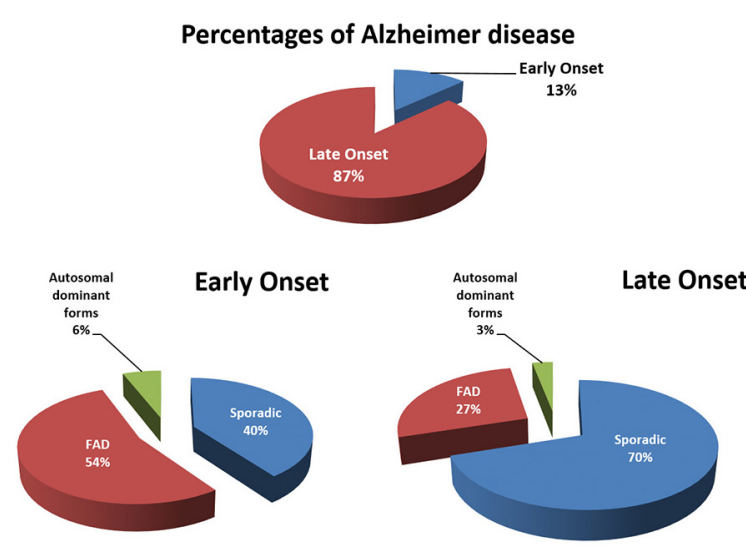

FIGURE 1 | Early [ $<65$ years; early-onset AD (EOAD)] and late onset [>65 years; late-onset AD (LOAD)] forms of Alzheimers disease (AD) subdivided in familial, sporadic and autosomal dominant forms of AD. "Familial" means that AD was observed in relatives of the first degree. In familial EOAD, the majority (54\%) is not yet linked to a chromosome, whereas $6 \%$ is inherited in an autosomal dominant way and linked to chromosome 14 (PS1), chromosome 1 (PS2) and chromosome 21 amyloid precursor protein (APP; Harvey et al., 2003; Mercy et al., 2008). In familial LOAD, the majority is not yet linked to a chromosome, whereas a minority is inherited in an autosomal dominant way. A subset has been linked to chromosome 12 (Pericak-Vance et al., 1997). Figure was updated in 2015. associated with $\mathrm{AD}$ consists of mutations in the genes encoding for the amyloid precursor protein (APP; chromosome 21), Presenilin 1 (PS1; chromosome 14) and Presenilin 2 (PS2; chromosome 1).

A large number of pathogenic mechanisms in $\mathrm{AD}$ have been identified (Jellinger, 2009) including proteasomal dysfunction, oxidative stress, mitochondrial dysfunction, fragmentation of Golgi complex, cellular/axonal transport disruption, mutation of molecular chaperones, dysfunctional neurotrophins, neuroinflammatory processes and more recently seeding (Jucker and Christen, 2013). All these complex mechanisms are interconnected resulting in cell dysfunction, neuron shrinkage and cell death such as in parts of the hippocampal complex and locus coeruleus (Mann et al., 1980; West et al., 1994; Heneka et al., 2006). It needs to be noted that neuron loss is not a widespread phenomenon in $\mathrm{AD}$ (Regeur et al., 1994) and that cell shrinkage, resulting in weight loss of the brain, erroneously suggested neuron loss, is occurring (Hoogendijk et al., 1995; Lee et al., 2015). The present review focusses on two mechanisms mentioned above; proteasomal dysfunction by a mutant form of ubiquitin $\mathrm{B}\left(\mathrm{UBB}^{+1}\right)$ and partially in combination with oxidative stress (Hope et al., 2003; Irmler et al., 2012; Braun et al., 2015), both contributing to disease-specific inclusions (van Leeuwen et al., 1998; Dennissen et al., 2012).

The neuropathogenesis of $\mathrm{AD}$ includes so called negative and positive lesions. Negative lesions describe the loss of cholinergic neurons in the brain, whereas positive lesions are the accumulation of abnormal/misfolded proteins known as deposits (Serrano-Pozo et al., 2011). This accumulation of putative toxic protein species in the brain of the patients is one common hallmark of many neurodegenerative diseases, such as $\mathrm{AD}$ and, as well, Parkinson's (PD) and Huntington's (HD) diseases (Fischer et al., 2003). These three diseases belong to a group sharing the common feature of the accumulation of insoluble protein deposits in neurons and are now designated "conformational diseases" coined as such (Lomas and Carrell, 2002). AD is associated with progressive accumulation of two hallmarks, namely extracellular Amyloid $\beta$ (A $\beta$ ) plaques and intracellular neurofibrillary tangles (NFTs; Selkoe, 2001; Duyckaerts et al., 2009) Currently there are no indications of increased $\mathrm{A} \beta$ and tau protein production in $\mathrm{AD}$ which suggests that the accumulation of these proteins is caused by a lack of cellular clearance (Olsson et al., 2003). The degradation pathway of these proteins remains elusive but autophagy is an attractive possibility (Lee et al., 2013; Nilsson and Saido, 2014). Although $\mathrm{A} \beta$ and tau do not seem to be substrates of the $26 \mathrm{~S}$ proteasome, both proteins are able to impair functioning of the 26S proteasome (Saido and Leissring, 2012). Further details concerning $A \beta$, tau, and the proteasome are given in the following paragraphs. 


\section{The A $\beta$ Peptide Hypothesis}

The amyloid hypothesis focuses on the endoproteolytic cleavage pathway of APP, a transmembrane protein (Glenner and Wong, 1984). This "hypothesis" is supported by the fact that $A \beta$ plaques are present in $\mathrm{AD}$ brains and that mutations in the APP gene are involved in the autosomal dominant inherited form of AD (Masters and Selkoe, 2012). APP is a precursor molecule which experience proteolysis to generate $A \beta$ species of different length. Normally, a cascade of endoproteolytic cleavages of APP by $\alpha$-, $\beta$ - and $\gamma$-secretases results in the production of both non-amyloidogenic (the $\alpha$-secretase pathway) and amyloidogenic ( $\beta$-secretase pathway) peptides (Figure 2). The $\gamma$-secretase cleavage is a heterogeneous event, so depending on the site of cleavage by this protease $A \beta$-peptides of different size are generated: $A \beta_{40}$ and $A \beta_{42}$ are the most common ones (Haass et al., 2012). The two additional amino acids in $A \beta_{42}$ compared to $A \beta_{40}$ render $A \beta_{42}$ more hydrophobic thereby making it more susceptible aggregate. Due to a higher rate of insolubility and fibrillization, $A \beta_{42}$ is more abundant than $A \beta_{40}$ in extracellular plaques. In many types of $A D$ the ratio of $A \beta_{42} / A \beta_{40}$ is increased (Masters and Selkoe, 2012). This ratio can also be influenced by mutations in the $\alpha$-secretase (ADAM 10), favoring the amyloidogenic pathway (Suh et al., 2013). A $\beta$ peptides eventually oligomerize to fibrils which eventually accumulate intracellularly, are secreted and promote synaptotoxicity by seeding (Duyckaerts et al., 2009). Three major types of $A \beta$ plaques can be distinguished in $A D$ : diffuse amyloid plaques, dense-core plaques and neuritic plaques (NPs; Serrano-Pozo et al., 2011). Currently, there is still an ongoing debate about which species is exactly more toxic: intracellular oligomers or extracellular plaques? A lot of mutations are found within the $\gamma$-secretase complex (PS1, PS2) which cause excessive production of $A \beta 42$. Excessive accumulation of $A \beta$ species and subsequent seeding is the initiating event in the pathogenesis of $\mathrm{AD}$ according to this hypothesis. It turned out that the formation of $\mathrm{A} \beta$ plaques in a transgenic $(\mathrm{tg})$ model of $\mathrm{AD}$ can be modulated by $\mathrm{UBB}^{+1}$ expression via $\gamma$-secretase and of this multimeric complex at least the presenilin expression (van Tijn et al., 2012; Gentier et al., 2015b).

Other studies showed genomic duplications in the APP locus in families suffering from early-onset AD (EOAD) with concurrent cerebral amyloid angiopathy. These data suggests as well that increased expression of APP has an important role in the AD disease etiology (Rovelet-Lecrux et al., 2006; Sleegers et al., 2006). In addition, the link between Down syndrome (DS) and $\mathrm{AD}$ regarding neuropathogenesis and dementia, supports the relevance of $A \beta$ even further, because DS patients have three copies of chromosome 21 and APP is located at the same chromosome. In $\mathrm{DS}, \mathrm{A} \beta$ plaques already appear around 30 years of life e.g., (van Leeuwen et al., 2006). Development of dementia in DS patients is the result of overproduction of toxic $A \beta$ species as a direct consequence of the triplication of the APP gene (Weksler et al., 2013). In addition, a coding mutation (A673T) in the APP gene was found in an Icelandic population which protects against $\mathrm{AD}$ and cognitive decline in the elderly without AD. This A673T mutation results in an approximately
$40 \%$ reduction in the formation of amyloidegenic peptides in vitro and provides proof of principle for the hypothesis that reducing the amyloidogenic cleavage of APP may protect against $\mathrm{AD}$ (Jonsson et al., 2012). At the present time, evidence is appearing which suggests that $A \beta$ is neither sufficient nor necessary in the development of $\mathrm{AD}$ but only related to it. This finding is based on the observation that the amount and distribution of $A \beta$ accumulation do not correlate with the degree of cognitive impairment and that $A \beta$ is present as well in the brains of cognitively normal elderly people (Drachman, 2014). The prevalence of amyloid pathology increased from age 50 to 90 years from $10 \%$ ( $95 \% \mathrm{CI}, 8-13 \%$ ) to $44 \%$ (95\% CI, 37-51\%) among participants with normal cognition (Jansen et al., 2015). In addition, $A \beta$ immunization trials in $A D$ patients have been up to now unsuccessful in terms of curing or ameliorating dementia probably because these clinical trials started too late in the disease process and even resulted in meningoencephalitis in $6 \%$ of the cases. e.g., (Holmes et al., 2008; Lannfelt et al., 2014). A limited clearance of pre-existing $\mathrm{A} \beta$ plaques was also shown in experimental studies with the same tg $\mathrm{AD}$ mouse model as used for our studies (Tucker et al., 2008; van Tijn et al., 2012). As mentioned before using line 85 we were able to lower the formation of $A \beta$ plaques. This shows again that an earlier start of immunization trials is an option (Reiman et al., 2012). Another strategy to lower the amount of $\mathrm{A} \beta$ plaques or signs of dementia is the use of $\gamma$-secretase inhibitors that were unsuccessful so far, because these trials were halted due to worsening of the outcomes (De Strooper, 2014). A detailed discussion on these trials and the biology of APP processing goes beyond the scope of the present review.

\section{The Tau Hypothesis}

This so-called "Tau and tangle hypothesis" suggests that hyperphosphorylated tau is the primary causative factor in $\mathrm{AD}$ development leading to neurotoxicity. This hypothesis is based on the observation that NFT density and distribution correlates with the clinical stage of the disease (Morris et al., 2011; Braak and Del Tredici, 2013).

The tau gene (located on chromosome 17) is translated into a protein found predominantly in nerve cells, concentrated in axons, in normal brain and the protein has six isoforms. It contains a microtubule-binding domain formed out of three or four repeating regions (tau $3 \mathrm{R}$ and tau $4 \mathrm{R}$ ) (Goedert et al., 2012). The history of Tau has been reviewed recently but mutations in the Tau gene have only be shown for tauopathies related to AD (Mandelkow and Mandelkow, 2012). Tau initiates and stabilizes neuronal microtubules, which are components of the cytoskeleton, by binding tubulin in healthy brain (Iqbal et al., 2009; Kadavath et al., 2015). When tau is hyperphoshorylated, the ability to bind microtubules is reduced. Accumulations of hyperphosphorylated and misfolded tau proteins are observed in affected neurons in AD. Under normal conditions tau is a soluble protein but it becomes insoluble in its hyperphosphorylated state. In contrast to the normal function of tau protein, the aberrant protein causes 


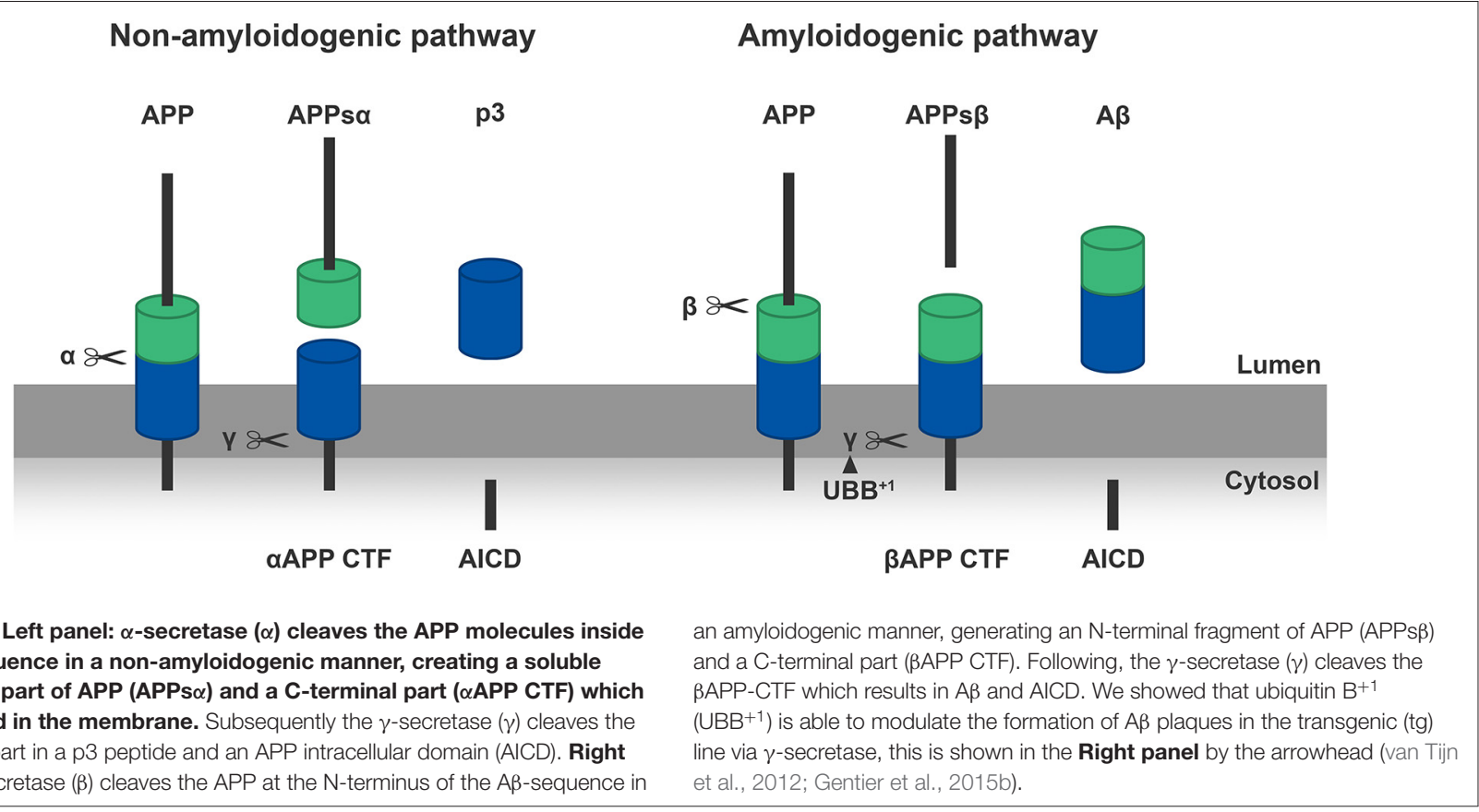

disruption of microtubules, dysregulated axonal transport, sequestration of normal tau and subsequently promotes selfassembly (Simic et al., 2009). Three kinds of tau aggregates can be differentiated in AD: pretangles and NFTs in the cell body of neurons, neuropil threads (NTs) in the dendrites, and dystrophic neurites associated with NPs in the axons (Duyckaerts et al., 2009). These different forms of tau are detected in our studies by using the MC1 antibody, recognizing aberrant tau in pretangles, and $\mathrm{CP} 13$, recognizing phosphorylated tau and appeared to coincide with the appearance of $\mathrm{UBB}^{+1}$. How $\mathrm{UBB}^{+1}$ is related to aberrant and phosphorylated Tau, both spatially and temporally needs to be determined. A common procedure to classify the degree of $\mathrm{AD}$ pathology is the so-called Braak staging (Stages I-VI) based on topographical and timedependent distribution of NFTs and NTs (Braak and Braak, 1991). It was generally accepted that the progression of tau pathology follows a consistent pattern of propagation, which initiates in the transentorhinal cortex and eventually affects all the subdivisions of the neocortex (Braak and Braak, 1995). Currently, however, more evidence is available suggesting that tau aggregation starts in other regions of the brain, such as the brainstem, in particular the locus coeruleus (Braak and Del Tredici, 2011). Based up on these data now also tau immunizations have started (e.g., Sankaranarayanan et al., 2015).

\section{The Ubiquitin Proteasome System and $\mathrm{UBB}^{+1}$}

The levels of many proteins must be highly regulated both spatially and temporally in order for cellular functions to proceed accurately (Hegde et al., 2014). The ubiquitin proteasome system (UPS) is one of the major intracellular mechanisms responsible for executing this process severely contributing to homeostasis in eukaryotic cells. Apart from cellular homeostasis, this system plays an essential role in maintaining neuronal functioning, regulation of chromatin structure, DNA repair, transcriptional regulation, cell cycle and cell division, synaptic development, maintaining synaptic connections and numerous other functions (Ciechanover, 2005). The UPS proteolytic pathway does this by the selective ATP-dependent degradation of target proteins such as shortlived, truncated or misfolded proteins by tagging these with polyubiquitin chains. In addition to the ubiquitination, other post transcriptional modifications such as SUMOylation and NEDDylation contribute to protein degradation (Dennissen et al., 2012) and autophagic processes are activated when the UPS capacity is exceeded (Lee et al., 2013; Nixon, 2013; Nilsson and Saido, 2014).

Ubiquitin (UBB) is a highly conserved signaling molecule of 76 amino acids with a molecular mass of $8.5 \mathrm{kDa}$, that acts in the membrane, nucleus, and cytoplasm of all eukaryotic cells (Gregori et al., 1995). The main function of this protein is a post translational modification by covalent attachment via an isopeptide bond between UBB and a target protein which is called ubiquitination. The addition of a chain of UBB moieties on the target molecule is called multiubiquitination. The C-terminal glycine (G76) of the UBB molecule will attach to an internal lysine $(\mathrm{K})$ of the target protein (Figure 3). After tagging the target protein with a polyubiquitin chain, the protein is subsequently translocated and degraded by a $26 \mathrm{~S}$ proteasome complex in an ATP-dependent manner.

The conjugation of $\mathrm{UBB}$ to the internal lysine residues $(\mathrm{K})$ of the target protein is mediated by a cascade of E1-activating, E2-conjugating, E3-ligating and E4-elongating enzymes, which are stepwise described in Figure 5. UBB is 


\section{0 \\ MQIFVKTLTGKTITLEVEPSDTIENVKAKIQDKEGIPP \\ 40 \\ 50 \\ DQQRLIFAGKQLEDGRTLSDYNIQKESTLHLVLRLTGG}

$\Delta \mathrm{GU}$

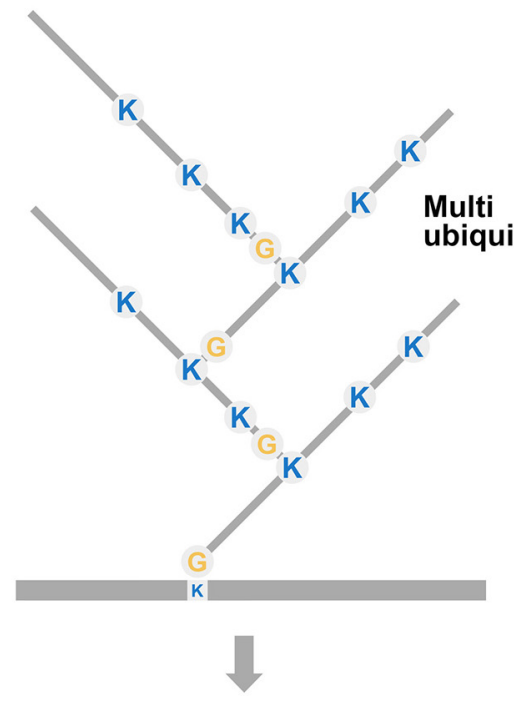

Proteasomal degradation

FIGURE 3 | Simplified scheme of the multiubiquitination process of proteasome substrates. In the ubiquitin proteasome system (UPS), a substrate (= a degron, such as a misfolded protein) is (poly)ubiquitinated via a number of enzymatic steps (E1, E2 and E3). The C-terminal glycine (G76) of the UBB molecule will attach to lysine moieties $(K)$ at positions 29, 48 and 63 which are involved in multiubiquitination and degradation. The UBB molecule "on top" of the target protein prone for degradation can be ubiquitinated itself, developing a multiubiquitination chain with at least four residues to be efficient for triggering proteasomal degradation (left panel). A GAGAG
Target protein

\section{Proteasomal dysfunction}

30

MQIFVKTLTGKTITLEVEPSDTIENVKAKIQDKEGIPP

$40 \quad 50 \quad 60 \quad 70$

DQQRLIFAGKQLEDGRTLSDYNIQKESTLHLVLRLRG

$80 \quad 90$

YADLREDPDRQDHHPGSGAO

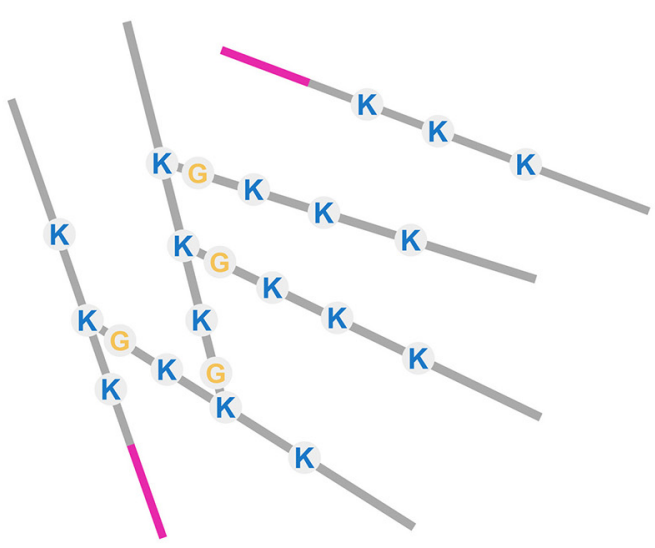

generated from a precursor protein which is cleaved by ubiquitin C-terminal hydrolases (UCHs). UBB becomes activated in an ATP-dependent manner by the enzyme E1 via a highenergy thiolester bond between the carboxyl group of UBB and the active-site cysteine of E1 enzyme (Pickart, 2001). Subsequently, activated UBB is conjugated to the active site of an E2 ubiquitin-conjugation enzyme by a transthioesterification reaction. Currently, at least 30 different E2 enzymes have been described in the human genome (Bhowmick et al., 2013). Thereafter, UBB is transferred to an internal lysine of the target protein by E3 ubiquitin-protein ligases. There are at least 600 E3 ligases encoded in the human genome (Bhowmick et al., 2013). E3 ligases mediate the ligation between UBB and the target protein resulting in the ubiquitination of the target protein (Ciechanover and Kwon, 2015). Two different types of E3 enzymes are known: one type, the Homologous to E6-associated protein C-terminus (HECT) binds the E2enzymes as well as the target protein and serves in this way as an intermediate docking station for UBB. A second type of E3-enzyme is the Real Interesting New Gene (RING) finger containing E3-ligase. In this instance, UBB is transferred directly motif is present at the C-terminus of UBB and a dinucleotide deletion $(\Delta G U)$ occurs adjacent to this motif which results in an 20 amino acids extension (red bar), called $\mathrm{UBB}^{+1}$ (see Figure 4). This causes the absence of G76, necessary for binding to the target protein, and consequently it is not able to ubiquitinate (Ciechanover and Kwon, 2015). Interestingly, E3 enzymes are able to form a "forked" polyubiquitin chain in which two ubiquitin chains are linked ot adjacent lysines on a preceding ubiquitin moiety (e.g., K29, K48 and K63). These forked polyubiquitin chains are relatively resistant to degradation by the 26S proteasome (Kim et al., 2009). from the E2-complex to the target protein by the RING-E3 ligase.

The multi-UBB chain linked with the lysine at position 48 (K48) has to be at least four residues long for efficient proteosomal targeting (Thrower et al., 2000). UBB has seven lysine residues indicating that diversity in polyubiquitin chain topology exists in vivo (Peng et al., 2003). As mentioned, the $\mathrm{K} 48$ bond involved in proteasome degradation is the most widely known and used topology. However, also different linkages exist like the K63 linkage which mediates non-proteolytic processes (Hadian et al., 2011) or the K11 linkage used for cell-cycle regulation and cell division (Matsumoto et al., 2010). The target protein undergoes several rounds of ubiquitination and in this way a polyubiquitin chain is formed (Ciechanover, 2014). Another, specialized type of E3 enzyme (E4, e.g., CHIP) is necessary for some substrates to be able to become polyubiquitinated to the desired length (Koegl et al., 1999; Hoppe, 2005).

$\mathrm{UBB}^{+1}$ is characterized as the first and only naturally occurring ubiquitin fusion degradation (UFD) substrate, is associated with neurodegeneration and ubiquitinated at K29 and 
DNA

GCTCTCTCTTACAGACTG

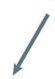

Normal RNA

CGA GAG AGA AUG UCU GAC

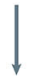

Normal Protein

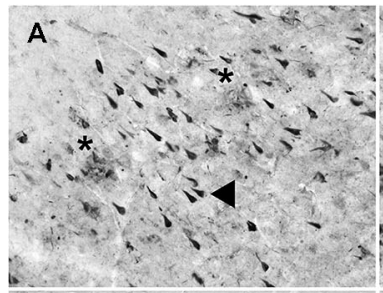

D

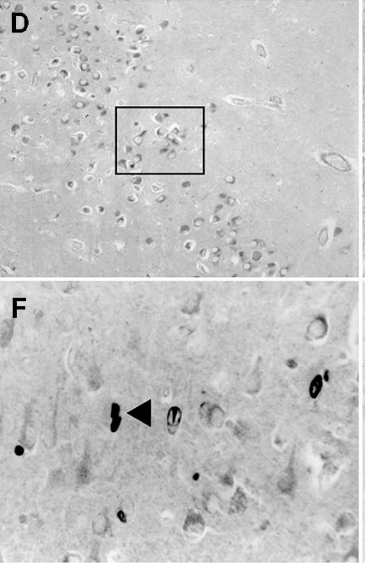

FIGURE 4 | Assembly-line slippage. Loss of two bases [ $\triangle \mathrm{GU}, \triangle \mathrm{GA}$ and other ones (van Den Hurk et al., 2001)] in the mRNA garbles the rest of the sequence (Vogel, 1998). Non-sense mRNA decay (NMD) requires a downstream intron (Maquat, 2015) that is present in APP, Neurofilament $\mathrm{H}$ and MAP2b genes. However, in the UBB gene, this downstream intron is lacking and the misframed transcript apparently escapes NMD. As shown in Figure 3 thereby the essential $\mathbf{C}$-terminus is lost. In (A-C) the resulting $\mathrm{UBB}^{+1}$

accumulation in neurofibrillary tangles (NFTs) (triangle) of the hippocampus of an AD patient and a similar one in Pick's disease (D,E) in Pick bodies of CA1 in the hippocampus is shown. Note in (A) the presence of neuritic plaques (NPs) indicated by a star. $(\mathbf{F}, \mathbf{G})$ Neurofilament $\mathrm{H}$ transcripts apparently undergo a similar process (exon 1. aa. VGAARDSRAA), the resulting $\mathrm{NFH}^{+1}$ protein accumulates in $\mathrm{CA} 1$ of the hippocampus of $\mathrm{AD}$ patients (triangle). $\mathrm{A}$ similar reaction was found for MAP2B ${ }^{+1}$ (for details, see van Leeuwen et al., 2000). Of course these immunohistochemical data require many controls to avoid cross reactivity (Swaab et al., 1977) as was done for $\mathrm{UBB}^{+1}$. (A-C) $50 \mu \mathrm{m}$ thick Vibratome sections, (D-F) $6 \mu \mathrm{m}$ think paraffin sections.

K48 (Lindsten et al., 2002). $\mathrm{UBB}^{+1}$ is also ubiquitinated at K63 which opens the possibility of additional effects of $\mathrm{UBB}^{+1}$ (e.g., kinase activation; van Tijn et al., 2012). In summary, variation in the length of the polyubiquitin chain and the ubiquitin linkage location determine the fate of the ubiquitinated proteins, a process that is most probably more complex than previously assumed (Ciechanover, 2014; Ciechanover and Kwon, 2015).

Subsequently, the polyubiquitin-protein conjugate is degraded by the $26 \mathrm{~S}$ proteasome complex by an ATP-dependent process (Peth et al., 2013; Figure 6). The abnormal protein is cleaved into short peptide fragments of 6-10 amino acids (Ihara et al., 2012) and the polyubiquitin chain is released. The polyubiquitin chain is degraded by UCHL3 (Dennissen et al., 2011) and further processed by de-ubiquitinating enzymes (DUBs) into monomeric ubiquitin.

\section{The Proteasome}

Polyubiquitinated proteins are translocated to the 26S proteasome which is described in detail in Figure 6. The proteasome has to fulfill a whole range of specialized functions: (1) cleavage of ubiquitin chains linked on the target protein; coined deubiquitination; (2) recognition and binding selectively to substrates prone to degradation; (3) chaperoning and unfolding of these substrates; (4) opening of the gates on each side of the $20 \mathrm{~S}$ subunit; and (5) driving the substrate into the proteolytic core center in the 20S cylinder (Wolf and Hilt, 2004). We have performed an extensive immunohistochemical screen of almost all subunits of the proteasome in the hippocampal complex of $\mathrm{AD}$ and non-demented controls to see if a differential expression pattern of these subunits could be related to $\mathrm{UBB}^{+1}$ (Zouambia et al., 2008). Therefore the proteasomal complex is briefly introduced.

The proteasome is a cylindrical complex of 2.5 MDa which consists of two 19S caps and a proteolytic 20S core (Bedford et al., 2010; Ciechanover and Kwon, 2015). The 20S core complex has a barrel shape comprised of four rings and each ring includes seven subunits. The outer two rings are made up by $7 \alpha$-subunits facilitating docking of the 19S caps. The proteolytic chamber is composed of two inner rings consisting of $\beta$-subunits where $\beta 1, \beta 2$ and $\beta 5$ show proteolytic active sites. The proteolytic activity can be specified in peptidyl-glutamyllike $(\beta 1)$, trypsin-like $(\beta 2)$ and chymotrypsin-like $(\beta 5)$ activity. Alternatively, $\beta 1 \mathrm{i}, \beta 2 \mathrm{i}$ and $\beta 5 \mathrm{i}$ can substitute for $\beta 1, \beta 2$ and $\beta 5$ causing a different composition of the $20 \mathrm{~S}$ complex which result in the immunoproteasome. These substitutions can be induced by pro-inflammatory (e.g., interferon- $\gamma$ ) cytokines resulting in immunoproteasomes, responsible for the generation of antigenic peptides presented by the MHC class I complex (Wolf and Hilt, 2004).

The 19S activator complexes consist of a base and a lid and are linked to each other via subunit regulatory particle nonATPase 10 (Rpn10; S5a in mammals, please note that here the yeast nomenclature is used whereas aliases for the same subunit can be found at sites such as Online Mendelian Inheritance in Man (OMIM) or Genecards). The base consists of 6 ATPases of the AAA-family of proteins called Regulatory particle triple A proteins 1-6 (Rpt1-Rpt6), 3 additional non-ATPase subunits Rpn1 and Rpn2; and Rpn10/S5a (Zouambia et al., 2008; Ciechanover, 2014). Rpt 5 binds the ubiquitinated substrate. The lid on top of the base is built up out of eight different subunits (Rpn3, Rpn5 to Rpn9, Rpn 11 and Rpn12). Rpn11 contains a conserved metallo-isopeptidase motif which is necessary for deubiquitylation and proteolysis of substrates. It is responsible for the deubiquitination of the targeted substrate after this has been threaded into the $20 \mathrm{~S}$ unit; for details, see Tsakiri and 


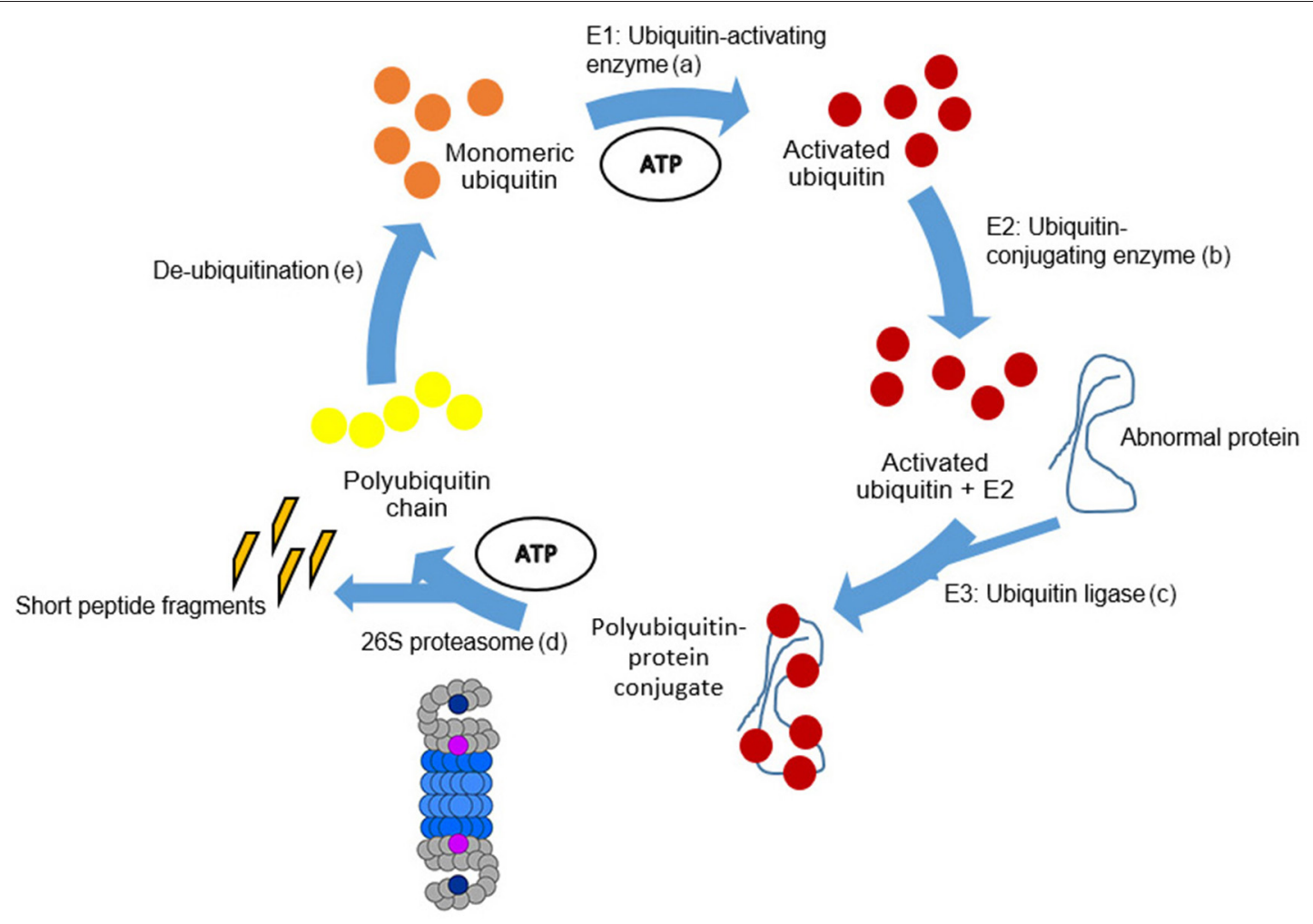

FIGURE 5 | Schematic representation of the UPS. The degradation process by the UPS can be divided into five steps. (a) Beginning with monomeric ubiquitin (orange circles). Ubiquitin becomes activated in an ATP-dependent manner by E1. (b) Activated ubiquitin (red circles) is conjugated by E2 enzymes. (c) Thereafter, UBB is transferred to an internal lysine of the target protein by E3 ligases. Following, activated and conjugated ubiquitin binds to the abnormal protein forming the polyubiquitin-protein conjugate. (d) Subsequently, the polyubiquitin-protein conjugate is degraded by the $26 \mathrm{~S}$ proteasome complex (Figure 5) by an ATP-dependent process (Peth et al., 2013). The abnormal protein is cleaved into short peptide fragments (orange pointed bars) and the polyubiquitin chain is released (yellow circles). (e) The polyubiquitin chain is split by de-ubiquitination enzymes into monomeric ubiquitins. For details, see Layfield et al. (2005).
Trougakos (2015). It has been shown in immunohistochemical experiments that the Rpt3 subunit of the base is activated at the transcript level and colocalizes with $\mathrm{UBB}^{+1}$ in NFT of tauopathies including $\mathrm{AD}$ but not in synucleinopathies. This upregulation and colocalization of Rpt3 (or subunit 6b; human alias) with $\mathrm{UBB}^{+1}$ suggests a neuronal reaction to compensate for an increased need to degrade aberrant proteins (Zouambia et al., 2008).

Ultimately, as stated above, the proteasome degrades the substrate into short peptides and, thereby, reusable ubiquitin is released by DUBs. This deubiquitination process is tightly regulated by enzymes called deubiquitinating enzymes (at least 183 DUBS are known) which are partly essential for neuronal functioning. These DUBs can be subdivided into five different classes: (1) the UCHs; (2) the ubiquitin specific proteases (USPs); (3) the ovarian tumor proteases (OTUs); (4) the Machado-Joseph Disease protein domain proteases (MJDs); and (5) the JAB1/MPN/Mov34 metalloenzymes (JAMMs; Todi and Paulson, 2011). DUBs are responsible for cleaving ubiquitin precursors, rescuing target substrates from degradation, cleaving the ubiquitin chain at the proteasome entrance, controlling epigenetic mechanisms by deubiquitinating histones, and for disassembly of unanchored ubiquitin chains generating single ubiquitin moieties (Komander et al., 2009). Since ubiquitination is a reversible process, DUBs are responsible for maintaining the balance between free UBB and processed UBB (de Vrij et al., 2004; Dennissen et al., 2012). Recently it turned out that extended ubiquitin species like $\mathrm{UBB}^{+1}$ are potent DUB inhibitors leading to accumulation of proteins (Krutauz et al., 2014). This suggests that downregulation of $\mathrm{UBB}^{+1}$ is an attractive strategy to restore neuronal function.

\section{UPS in AD}

There is compelling evidence that the UPS is impaired in many tauopathies such as $\mathrm{AD}$ and is involved in the accumulation of ubiquitinated proteins in $\mathrm{AD}$ brains (de Vrij et al., 2004; Ciechanover and Kwon, 2015). $\mathrm{UBB}^{+1}$ is formed during the transcription of the UBB gene by a mechanism that still has to be elucidated, but widespread DNA-RNA sequence differences do occur of which the mechanism is becoming clear (van Leeuwen et al., 1998; Gerez et al., 2005; Li et al., 2011, 2012; Wang et al., 2014). This process was coined molecular misreading by our group or RNA-DNA differences (RDD) by Cheungs group. 


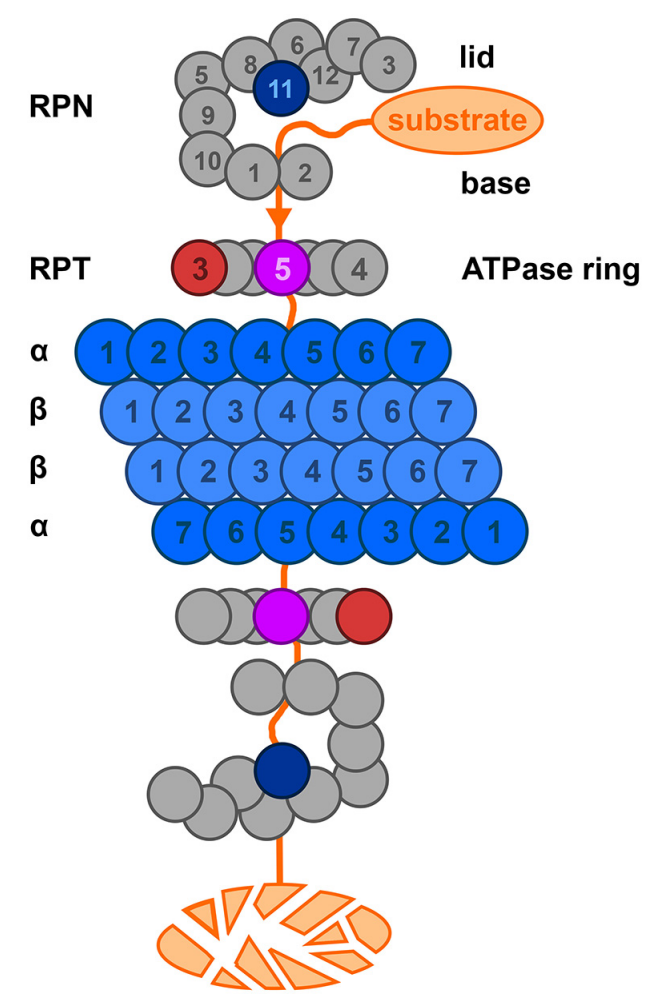

FIGURE 6 | A representation of the 26 S proteasome complex based on Kostova and Wolf (2003). The lid consists of eight non-ATP-ase subunits, the base consists of 6 ATP-ase and 3 non-ATP-ase subunits. Please note here that the yeast nomenclature is used. The catalytic core (blue) is a barrel-like structure and consists of four stacked heptameric rings. The function of many of the lid, base and ATPase ring subunits such as Rpt3 (red); Rpt 5 (purple); Rpn 11 (blue) have been described. For details, see text, Tsakiri and Trougakos (2015).

$\mathrm{UBB}^{+1}$ accumulation is found in the neurons of all AD patients and it colocalizes with markers like MC1 and CP13 for NFTS, "kinky and curly" fibers, NTs and dystrophic neurites in plaques (van Leeuwen et al., 1998).

$\mathrm{UBB}^{+1}$ mRNA was present in all tested brain specimens of non-demented controls, tauo- and synucleinopathies, while the aberrant protein specifically accumulates not not only in all tauopathies investigated so far (e.g., AD; Fischer et al., 2003) but also in polyglutaminopathies (de Pril et al., 2004). Interestingly, the accumulation of the $\mathrm{UBB}^{+1}$ protein seems not to be initiated by an increase in molecular misreading, as the UBB mRNA concentration measured in cells from temporal cortices of $\mathrm{AD}$ patient aged between $54-88$ is not increased, nor is it in non-demented controls aged between 38-90 (Gerez et al., 2005). So, question like the driving force of this process, the mechanism of molecular misreading and the difference in protein expression between tauopathies and synucleinopathies remain to be determined. A mechanism to check for errors in mRNA was described by the group of Maquat (Nagy and Maquat, 1998). Apparently $\mathrm{UBB}^{+1}$ transcripts escape mRNA surveillance as a downstream intron ( $>50$ nucleotides downstream the mutation) is required which lacks in the UBB gene. This process is also called non-sense mediated RNA decay (NMD; Maquat, 2015).

So $\mathrm{UBB}^{+1}$ accumulates specifically in tauo- and polyglutaminopathies. Apparently, the UPS partly contributes to these phenomena:

a. Ubiquitination of $\mathrm{UBB}^{+1}$ is mediated by the enzymes E2-25K (Ko et al., 2010) and E3 ligases TRIP12 and HUWE1 (Park et al., 2009; Poulsen et al., 2012). E2-25K has an important role in providing a functional interaction between $\mathrm{UBB}^{+1}$ and $\mathrm{A} \beta$ toxicity (Ko et al., 2010).

b. $\mathrm{UBB}^{+1}$ chains seem to be resistant to disassembly by the DUB isopeptidase $\mathrm{T}$, as $\mathrm{UBB}^{+1}$ lacks the $\mathrm{C}$-terminal glycine residue (Lam et al., 2000).

c. Another explanation for $\mathrm{UBB}^{+1}$ accumulation is that it may be due to the inefficient hydrolysis of the C-terminus of $\mathrm{UBB}^{+1}$ by the DUB. UCHL3, possibly of the oxidative stress in neurodegenerative diseases (Dennissen et al., 2011).

d. Furthermore it has been shown that $\mathrm{UBB}^{+1}$ is a few amino acids too short to be efficiently degraded by the proteasome (Verhoef et al., 2009).

e. At low levels, the $\mathrm{UBB}^{+1}$ protein will be polyubiquitinated and degraded by the proteasome itself. However, at higher levels it will act as an inhibitor of the proteasome (right panel of Figure 3; van Tijn et al., 2007). Decreased proteasome activity has been shown in affected brain areas (e.g., hippocampus and cortex) of AD patients (Keller et al., 2000). The UPS exhibited a failure in proteasomal activity in cortical brain areas in AD (López Salon et al., 2000; Zouambia et al., 2008). Interestingly, the accumulation of $\mathrm{A} \beta$ in extracellular plaques may have an additional UPS inhibition, an effect shown in a cell free system (Gregori et al., 1995), in neuronal primary cultures (Lopez Salon et al., 2003) and in several AD tg mouse models (Almeida et al., 2006; Tseng et al., 2008). In addition, paired helical filaments (PHFs) isolated from $\mathrm{AD}$ brains are able to inhibit the proteasome via the $20 \mathrm{~S}$ core (Keck et al., 2003). Moreover, the UPS inhibition not only increases the accumulation of $\mathrm{UBB}^{+1}$, but it also increases the deposition of hyperphosphorylated tau in NFTs (Morishima-Kawashima et al., 1993; Hol et al., 2005).

f. Earlier it was reported that $\mathrm{UBB}^{+1}$ causes neuritic beading, impairment of mitochondrial movements, mitochondrial stress and degeneration of primary neurons (Tan et al., 2007). The underlying mechanism may be due to mitochondrial dysfunction as we showed in a yeast strain that $\mathrm{UBB}^{+1}$ disturbs the UPS which causes mitochondrial stress and apoptosis. An unexpected enhancement of basic amino acid synthesis (arginine, ornithine and lysine) at mitochondria was induced by the expression of $\mathrm{UBB}^{+1}$ and this increase was identified as the decisive toxic event. This could be reversed by Cdc48/Vms1-mediated proteolysis which propose this pathway as a novel target for preventing neuronal dysfunction in $\mathrm{AD}$ (Braun et al., 2015).

g. It was shown that $\mathrm{UBB}^{+1}$ expression induces expression of heat-shock proteins (HSPs). This priming of the chaperone system promotes a subsequent resistance to oxidative stress (Hope et al., 2003). 
These data suggest that the UPS is a central component in the pathogenesis of $\mathrm{AD}$, a hypothesis recently firmly supported by other studies [Manavalan et al., 2013; International Genomics of Alzheimer's Disease Consortium (IGAP), 2015].

To elucidate the effects of $\mathrm{UBB}^{+1}$ accumulation in the brain, we generated a tg mouse line (line 3413/donated to Jackson \#008833) which shows overexpression of human $\mathrm{UBB}^{+1}$ in neurons of the postnatal brain, with strongest neuronal expression in the forebrain. In in vivo studies, a different behavioral phenotype from wild-type controls was found in the $3413 \mathrm{tg}$ mice showing deficits in spatial memory retention in the Morris water maze (MWM) as well as deficits in context-dependent fear conditioning (FC) compared with WT mice. The proteome also showed changes compatible with $\mathrm{AD}$ (Fischer et al., 2009). Furthermore an unexpected result of line 3413 were changes in spontaneous breathing patterns and an altered response to hypoxic conditions as revealed in a functional analysis in the German Mouse Clinic. These data were anatomically supported by strong $\mathrm{UBB}^{+1}$ immunoreactivity in NFTs in brainstem regions of tg mouse line 3413 and validated in the same human $\mathrm{AD}$ brainstem regions such as the parabrachial nucleus (PBN) and the nucleus of the solitary tract (NTS; Irmler et al., 2012). It is suggested that brainstem dysfunction (e.g., respiration problems) is an early symptom as a result of UPS dysfunction. Indeed our data are consistent with respiratory symptoms also observed in $\mathrm{AD}$ patients (for details, see Irmler et al., 2012). This study confirms the power of a complete phenotypic screening of a tg line, such as was performed by the German Mouse Clinic. The focus in AD research has so far been on the entorhinal cortex, temporal cortex and hippocampus while the brainstem has been under investigated. Very recently, a study appeared showing significant total volume reduction and deformations in the brainstem of AD patients (Lee et al., 2015). These data together (e.g., cognitive and respiratory dysfunction)

\section{References}

Almeida, C. G., Takahashi, R. H., and Gouras, G. K. (2006). Beta-amyloid accumulation impairs multivesicular body sorting by inhibiting the ubiquitinproteasome system. J. Neurosci. 26, 4277-4288. doi: 10.1523/jneurosci.5078-05. 2006

Alzheimer's Association (2012). 2012 Alzheimer's disease facts and figures. Alzheimers Dement. 8, 131-168. doi: 10.1016/j.jalz.2012.02.001

Barnes, D. E., and Yaffe, K. (2011). The projected effect of risk factor reduction on Alzheimer's disease prevalence. Lancet Neurol. 10, 819-828. doi: 10. 1016/s1474-4422(11)70072-2

Bedford, L., Paine, S., Sheppard, P. W., Mayer, R. J., and Roelofs, J. (2010). Assembly, structure and function of the $26 \mathrm{~S}$ proteasome. Trends Cell Biol. 20, 391-401. doi: 10.1016/j.tcb.2010.03.007

Bhowmick, P., Pancsa, R., Guharoy, M., and Tompa, P. (2013). Functional diversity and structural disorder in the human ubiquitination pathway. PLoS One 8:e65443. doi: 10.1371/journal.pone.0065443

Braak, H., and Braak, E. (1991). Neuropathological stageing of Alzheimer-related changes. Acta Neuropathol. 82, 239-259. doi: 10.1007/bf00308809

Braak, H., and Braak, E. (1995). Staging of Alzheimer's disease-related neurofibrillary changes. Neurobiol. Aging 16, 271-278; discussion 278-284. doi: 10.1016/0197-4580(95)00021-6

Braak, H., and Del Tredici, K. (2011). The pathological process underlying Alzheimer's disease in individuals under thirty. Acta Neuropathol. 121, 171-181. doi: 10.1007/s00401-010-0789-4 highlight the pivotal role of $\mathrm{UBB}^{+1}$ in basic mechanisms like homeostasis and breathing. According to Maslow's hierarchy (Maslow, 1943), these basal levels needs to be fulfilled to jump to the next level of satisfaction.

\section{Suggestions for Experimental Follow Up Work}

The topographic mapping of $\mathrm{UBB}^{+1}$ in the brain of mouse line 3413 with most intense site of $\mathrm{UBB}^{+1}$ accumulation in the forebrain and brainstem, show that line 3413 is not only useful for $\mathrm{AD}$ research (Gentier et al., 2015a) but also for studying other conformational diseases like HD and Familial encephalopathy with neuroserpin inclusion bodies (FENIB; Schipanski et al., 2014). This FENIB tg line was crossed with line 3413 and resulted in an effect on endoplasmic reticulum associated degradation (ERAD). Line 3413 was also useful when crossbred with mouse Line 85 [carrying the Swedish double mutation (K594M/N595L)] and human PS1 with a deletion of exon 9 (APPPS1; Jankowsky et al., 2004) regarding the modulation of the $A \beta 42$ plaque load at younger age and the unexpected rise in $\gamma$-secretase activity (Gentier et al., 2015b).

The contribution of the UPS compounds with regard to degrading $\mathrm{UBB}^{+1}$ can be addressed in yeast around three objectives. (1) Which are the lethal variants of $\mathrm{UBB}^{+1}$ ? (2) What is the role of the AAA-ATPases Cdc48/VCP and Rpt1-6 in degrading $\mathrm{UBB}^{+1}$ ? and (3) What is the role of DUBs in modifying $\mathrm{UBB}^{+1}$ and modulating its cytotoxicity?

\section{Acknowledgments}

The authors are very grateful for the critical remarks of Prof. DA Hopkins, HWM. Steinbusch and Drs J. Stevens and the financial support of ISAO project \#09-514.

Braak, H., and Del Tredici, K. (2013). Evolutional aspects of Alzheimer's disease pathogenesis. J. Alzheimers. Dis. 33(Suppl. 1), S155-S161. doi: 10.3233/JAD2012-129029

Braun, R. J., Sommer, C., Leibiger, C., Gentier, R. J., Dumit, V. I., Paduch, K., et al. (2015). Accumulation of basic amino acids at mitochondria dictates the cytotoxicity of aberrant ubiquitin. Cell Rep. 10, 1557-1571. doi: 10.1016/j. celrep.2015.02.009

Ciechanover, A. (2005). Proteolysis: from the lysosome to ubiquitin and the proteasome. Nat. Rev. Mol. Cell Biol. 6, 79-87. doi: 10.1038/nrm1552

Ciechanover, A. (2014). The complexity of recognition of ubiquitinated substrates by the 26S proteasome. Biochim. Biophys. Acta 1843, 86-96. doi: 10.1016/ j.bbamcr.2013.07.007

Ciechanover, A., and Kwon, Y. T. (2015). Degradation of misfolded proteins in neurodegenerative diseases: therapeutic targets and strategies. Exp. Mol. Med. 47:e147. doi: 10.1038/emm.2014.117

Dennissen, F. J., Kholod, N., Hermes, D. J., Kemmerling, N., Steinbusch, H. W., Dantuma, N. P., et al. (2011). Mutant ubiquitin $(\mathrm{UBB}+1)$ associated with neurodegenerative disorders is hydrolyzed by ubiquitin C-terminal hydrolase L3 (UCH-L3). FEBS Lett. 585, 2568-2574. doi: 10.1016/j.febslet.2011. 06.037

Dennissen, F. J., Kholod, N., and van Leeuwen, F. W. (2012). The ubiquitin proteasome system in neurodegenerative diseases: culprit, accomplice or victim? Prog. Neurobiol. 96, 190-207. doi: 10.1016/j.pneurobio.2012.01.003

de Pril, R., Fischer, D. F., Maat-Schieman, M. L., Hobo, B., De Vos, R. A., Brunt, E. R., et al. (2004). Accumulation of aberrant ubiquitin induces aggregate 
formation and cell death in polyglutamine diseases. Hum. Mol. Genet. 13, 1803-1813. doi: $10.1093 / \mathrm{hmg} / \mathrm{ddh} 188$

De Strooper, B. (2014). Lessons from a failed gamma-secretase Alzheimer trial. Cell 159, 721-726. doi: 10.1016/j.cell.2014.10.016

de Vrij, F. M., Fischer, D. F., van Leeuwen, F. W., and Hol, E. M. (2004). Protein quality control in Alzheimer's disease by the ubiquitin proteasome system. Prog. Neurobiol. 74, 249-270. doi: 10.1016/j.pneurobio.2004.10.001

Drachman, D. A. (2014). The amyloid hypothesis, time to move on: Amyloid is the downstream result, not cause, of Alzheimer's disease. Alzheimers Dement. 10, 372-380. doi: 10.1016/j.jalz.2013.11.003

Duyckaerts, C., Delatour, B., and Potier, M. C. (2009). Classification and basic pathology of Alzheimer disease. Acta Neuropathol. 118, 5-36. doi: 10. 1007/s00401-009-0532-1

Fischer, D. F., De Vos, R. A., van Dijk, R., De Vrij, F. M., Proper, E. A., Sonnemans, M. A., et al. (2003). Disease-specific accumulation of mutant ubiquitin as a marker for proteasomal dysfunction in the brain. FASEB J. 17, 2014-2024. doi: 10.1096/fj.03-0205com

Fischer, D. F., van Dijk, R., van Tijn, P., Hobo, B., Verhage, M. C., van Der Schors, R. C., et al. (2009). Long-term proteasome dysfunction in the mouse brain by expression of aberrant ubiquitin. Neurobiol. Aging 30, 847-863. doi: 10.1016/j. neurobiolaging.2008.06.009

Gentier, R. J., Verheijen, B. M., Zamboni, M., Stroeken, M. M., Hermes, D. J., Kuesters, B., et al. (2015a). Localization of mutant ubiquitin in the brain of a transgenic mouse line with proteasomal inhibition and its validation at specific sites in Alzheimer's disease. Front. Neuroanat. 9:26. doi: 10.3389/fnana.2015. 00026

Gentier, R. J. G., van Leeuwen, F. W., Verheijen, L. M., Steinbusch, H. W. M., Grim, M. O., Haupenthal, V. J., et al. (2015b). A $\beta$ plaque formation and impaired protein quality control interact via $\gamma$-secretase and result in a behavioural phenotype consistent with AD. Neurodegenerative Diseases 15(Suppl.1), 1246.

Gerez, L., de Haan, A., Hol, E. M., Fischer, D. F., van Leeuwen, F. W., van Steeg, H., et al. (2005). Molecular misreading: the frequency of dinucleotide deletions in neuronal mRNAs for beta-amyloid precursor protein and ubiquitin B. Neurobiol. Aging 26, 145-155. doi: 10.1016/j.neurobiolaging.2004.03.011

Glenner, G. G., and Wong, C. W. (1984). Alzheimer's disease and Down's syndrome: sharing of a unique cerebrovascular amyloid fibril protein. Biochem. Biophys. Res. Commun. 122, 1131-1135. doi: 10.1016/0006-291x(84)91209-9

Goedert, M., Ghetti, B., and Spillantini, M. G. (2012). Frontotemporal dementia: implications for understanding Alzheimer disease. Cold Spring Harb. Perspect. Med. 2:a006254. doi: 10.1101/cshperspect.a006254

Gregori, L., Fuchs, C., Figueiredo-Pereira, M. E., van Nostrand, W. E., and Goldgaber, D. (1995). Amyloid beta-protein inhibits ubiquitin-dependent protein degradation in vitro. J. Biol. Chem. 270, 19702-19708. doi: 10.1074/jbc. 270.34.19702

Haass, C., Kaether, C., Thinakaran, G., and Sisodia, S. (2012). Trafficking and proteolytic processing of APP. Cold Spring Harb. Perspect. Med. 2:a006270. doi: 10.1101/cshperspect.a006270

Hadian, K., Griesbach, R. A., Dornauer, S., Wanger, T. M., Nagel, D., Metlitzky, M., et al. (2011). NF-kappaB essential modulator (NEMO) interaction with linear and lys-63 ubiquitin chains contributes to NF-kappaB activation. J. Biol. Chem. 286, 26107-26117. doi: 10.1074/jbc.m111.233163

Harvey, R. J., Skelton-Robinson, M., and Rossor, M. N. (2003). The prevalence and causes of dementia in people under the age of 65 years. J. Neurol. Neurosurg. Psychiatry. 74, 1206-1209. doi: 10.1136/jnnp.74.9.1206

Hegde, A. N., Haynes, K. A., Bach, S. V., and Beckelman, B. C. (2014). Local ubiquitin-proteasome-mediated proteolysis and long-term synaptic plasticity. Front. Mol. Neurosci. 7:96. doi: 10.3389/fnmol.2014.00096

Heneka, M. T., Ramanathan, M., Jacobs, A. H., Dumitrescu-Ozimek, L., BilkeiGorzo, A., Debeir, T., et al. (2006). Locus ceruleus degeneration promotes Alzheimer pathogenesis in amyloid precursor protein 23 transgenic mice. J. Neurosci. 26, 1343-1354. doi: 10.1523/jneurosci.4236-05.2006

Hol, E. M., van Leeuwen, F. W., and Fischer, D. F. (2005). The proteasome in Alzheimer's disease and Parkinson's disease: lessons from ubiquitin $\mathrm{B}+1$. Trends Mol. Med. 11, 488-495. doi: 10.1016/j.molmed.2005.09.001

Holmes, C., Boche, D., Wilkinson, D., Yadegarfar, G., Hopkins, V., Bayer, A., et al. (2008). Long-term effects of Abeta42 immunisation in Alzheimer's disease: follow-up of a randomised, placebo-controlled phase I trial. Lancet 372, 216-223. doi: 10.1016/S0140-6736(08)61075-2
Holton, P., Ryten, M., Nalls, M., Trabzuni, D., Weale, M. E., Hernandez, D., et al. (2013). Initial assessment of the pathogenic mechanisms of the recently identified Alzheimer risk Loci. Ann. Hum. Genet. 77, 85-105. doi: 10.1111/ahg. 12000

Hoogendijk, W. J., Pool, C. W., Troost, D., van Zwieten, E., and Swaab, D. F. (1995). Image analyser-assisted morphometry of the locus coeruleus in Alzheimer's disease, Parkinson's disease and amyotrophic lateral sclerosis. Brain 118(Pt. 1), 131-143. doi: 10.1093/brain/118.1.131

Hope, A. D., De Silva, R., Fischer, D. F., Hol, E. M., van Leeuwen, F. W., and Lees, A. J. (2003). Alzheimer's associated variant ubiquitin causes inhibition of the 26S proteasome and chaperone expression. J. Neurochem. 86, 394-404. doi: 10. 1046/j.1471-4159.2003.01844.x

Hoppe, T. (2005). Multiubiquitylation by E4 enzymes: 'one size' doesn't fit all. Trends Biochem. Sci. 30, 183-187. doi: 10.1016/j.tibs.2005.02.004

Ihara, Y., Morishima-Kawashima, M., and Nixon, R. (2012). The ubiquitinproteasome system and the autophagic-lysosomal system in Alzheimer disease. Cold Spring Harb. Perspect. Med. 2:a006361. doi: 10.1101/cshperspect. a006361

International Genomics of Alzheimer's Disease Consortium (IGAP) (2015). Convergent genetic and expression data implicate immunity in Alzheimer's disease. Alzheimers Dement. 11, 658-671. doi: 10.1016/j.jalz.2014.05.1757

Iqbal, K., Liu, F., Gong, C. X., Alonso Adel, C., and Grundke-Iqbal, I. (2009). Mechanisms of tau-induced neurodegeneration. Acta Neuropathol. 118, 53-69. doi: 10.1007/s00401-009-0486-3

Irmler, M., Gentier, R. J., Dennissen, F. J., Schulz, H., Bolle, I., Hölter, S. M., et al. (2012). Long-term proteasomal inhibition in transgenic mice by $\mathrm{UBB}(+1)$ expression results in dysfunction of central respiration control reminiscent of brainstem neuropathology in Alzheimer patients. Acta Neuropathol. 124, 187-197. doi: 10.1007/s00401-012-1003-7

Jankowsky, J. L., Fadale, D. J., Anderson, J., Xu, G. M., Gonzales, V., Jenkins, N. A., et al. (2004). Mutant presenilins specifically elevate the levels of the 42 residue beta-amyloid peptide in vivo: evidence for augmentation of a 42 specific gamma secretase. Hum. Mol. Genet. 13, 159-170. doi: 10.1093/hmg/ ddh019

Jansen, W. J., Ossenkoppele, R., Knol, D. L., Tijms, B. M., Scheltens, P., Verhey, F. R., et al. (2015). Prevalence of cerebral amyloid pathology in persons without dementia: a meta-analysis. JAMA 313, 1924-1938. doi: 10.1001/jama. 2015.4668

Jellinger, K. A. (2009). Recent advances in our understanding of neurodegeneration. J. Neural Transm. 116, 1111-1162. doi: 10.1007/s00702009-0240-y

Jonsson, T., Atwal, J. K., Steinberg, S., Snaedal, J., Jonsson, P. V., Bjornsson, S., et al. (2012). A mutation in APP protects against Alzheimer's disease and age-related cognitive decline. Nature 488, 96-99. doi: 10.1038/nature11283

Jonsson, T., Stefansson, H., Steinberg, S., Jonsdottir, I., Jonsson, P. V., Snaedal, J., et al. (2013). Variant of TREM2 associated with the risk of Alzheimer's disease. N. Engl. J. Med. 368, 107-116. doi: 10.1056/NEJMoa1211103

Jucker, M., and Christen, Y. (2013). Proteopathic Seeds and Neurodegenerative Diseases. Heidelberg: Springer.

Kadavath, H., Hofele, R. V., Biernat, J., Kumar, S., Tepper, K., Urlaub, H., et al. (2015). Tau stabilizes microtubules by binding at the interface between tubulin heterodimers. Proc. Natl. Acad. Sci. U S A 112, 7501-7506. doi: 10.1073/pnas. 1504081112

Keck, S., Nitsch, R., Grune, T., and Ullrich, O. (2003). Proteasome inhibition by paired helical filament-tau in brains of patients with Alzheimer's disease. J. Neurochem. 85, 115-122. doi: 10.1046/j.1471-4159.2003.01642.x

Keller, J. N., Hanni, K. B., and Markesbery, W. R. (2000). Impaired proteasome function in Alzheimer's disease. J. Neurochem. 75, 436-439. doi: 10.1046/ j.1471-4159.2000.0750436.x

Kim, H. T., Kim, K. P., Uchiki, T., Gygi, S. P., and Goldberg, A. L. (2009). S5a promotes protein degradation by blocking synthesis of nondegradable forked ubiquitin chains. EMBO J. 28, 1867-1877. doi: 10.1038/emboj.2009.115

Ko, S., Kang, G. B., Song, S. M., Lee, J. G., Shin, D. Y., Yun, J. H., et al. (2010). Structural basis of E2-25K/UBB+1 interaction leading to proteasome inhibition and neurotoxicity. J. Biol. Chem. 285, 36070-36080. doi: 10.1074/jbc. M110.145219

Koegl, M., Hoppe, T., Schlenker, S., Ulrich, H. D., Mayer, T. U., and Jentsch, S. (1999). A novel ubiquitination factor, E4, is involved in multiubiquitin chain assembly. Cell 96, 635-644. doi: 10.1016/s0092-8674(00)80574-7 
Komander, D., Clague, M. J., and Urbé, S. (2009). Breaking the chains: structure and function of the deubiquitinases. Nat. Rev. Mol. Cell Biol. 10, 550-563. doi: $10.1038 / \mathrm{nrm} 2731$

Kostova, Z., and Wolf, D. H. (2003). For whom the bell tolls: protein quality control of the endoplasmic reticulum and the ubiquitinproteasome connection. EMBO J. 22, 2309-2317. doi: 10.1093/emboj/ $\operatorname{cdg} 227$

Krutauz, D., Reis, N., Nakasone, M. A., Siman, P., Zhang, D., Kirkpatrick, D. S., et al. (2014). Extended ubiquitin species are protein-based DUB inhibitors. Nat. Chem. Biol. 10, 664-670. doi: 10.1038/nchembio.1574

Lam, Y. A., Pickart, C. M., Alban, A., Landon, M., Jamieson, C., Ramage, R., et al. (2000). Inhibition of the ubiquitin-proteasome system in Alzheimer's disease. Proc. Natl. Acad. Sci. U S A 97, 9902-9906. doi: 10.1073/pnas.170 173897

Lannfelt, L., Möller, C., Basun, H., Osswald, G., Sehlin, D., Satlin, A., et al. (2014). Perspectives on future Alzheimer therapies: amyloid-beta protofibrils-a new target for immunotherapy with BAN2401 in Alzheimer's disease. Alzheimers Res. Ther. 6:16. doi: 10.1186/alzrt246

Layfield, R., Lowe, J., and Bedford, L. (2005). The ubiquitin-proteasome system and neurodegenerative disorders. Essays Biochem. 41, 157-171. doi: 10. 1042/eb0410157

Lee, M. J., Lee, J. H., and Rubinsztein, D. C. (2013). Tau degradation: the ubiquitinproteasome system versus the autophagy-lysosome system. Prog. Neurobiol. 105, 49-59. doi: 10.1016/j.pneurobio.2013.03.001

Lee, J. H., Ryan, J., Andreescu, C., Aizenstein, H., and Lim, H. K. (2015). Brainstem morphological changes in Alzheimer's disease. Neuroreport 26, 411-415. doi: 10.1097/wnr.0000000000000362

Li, M., Wang, I. X., and Cheung, V. G. (2012). Response to comments on "Widespread RNA and DNA sequence differences in the human transcriptome". Science 335:1302. doi: 10.1126/science.1210419

Li, M., Wang, I. X., Li, Y., Bruzel, A., Richards, A. L., Toung, J. M., et al. (2011). Widespread RNA and DNA sequence differences in the human transcriptome. Science 333, 53-58. doi: 10.1126/science.1207018

Lindsten, K., De Vrij, F. M., Verhoef, L. G., Fischer, D. F., van Leeuwen, F. W., Hol, E. M., et al. (2002). Mutant ubiquitin found in neurodegenerative disorders is a ubiquitin fusion degradation substrate that blocks proteasomal degradation. J. Cell Biol. 157, 417-427. doi: 10.1083/jcb.200111034

Lomas, D. A., and Carrell, R. W. (2002). Serpinopathies and the conformational dementias. Nat. Rev. Genet. 3, 759-768. doi: 10.1038/nrg907

López Salon, M., Morelli, L., Castaño, E. M., Soto, E. F., and Pasquini, J. M. (2000). Defective ubiquitination of cerebral proteins in Alzheimer's disease. J. Neurosci. Res. 62, 302-310. doi: 10.1002/1097-4547(20001015)62:2<302::aid-jnr15>3.0. co;2-1

Lopez Salon, M., Pasquini, L., Besio Moreno, M., Pasquini, J. M., and Soto, E. (2003). Relationship between beta-amyloid degradation and the $26 \mathrm{~S}$ proteasome in neural cells. Exp. Neurol. 180, 131-143. doi: 10.1016/s00144886(02)00060-2

Manavalan, A., Mishra, M., Feng, L., Sze, S. K., Akatsu, H., and Heese, K. (2013). Brain site-specific proteome changes in aging-related dementia. Exp. Mol. Med. 45:e39. doi: 10.1038/emm.2013.76

Mandelkow, E. M., and Mandelkow, E. (2012). Biochemistry and cell biology of tau protein in neurofibrillary degeneration. Cold Spring Harb. Perspect. Med. 2:a006247. doi: 10.1101/cshperspect.a006247

Mann, D. M., Lincoln, J., Yates, P. O., Stamp, J. E., and Toper, S. (1980). Changes in the monoamine containing neurones of the human CNS in senile dementia. Br. J. Psychiatry 136, 533-541. doi: 10.1192/bjp.136.6.533

Maquat, L. E. (2015). The amazing web of post-transcriptional gene control: the sum of small changes can make for significant consequences. RNA 21, 488-489. doi: 10.1261/rna.049718.115

Maslow, A. H. (1943). A theory of human motivation. Psychol. Rev. 50, 370-396.

Masters, C. L., and Selkoe, D. J. (2012). Biochemistry of amyloid beta-protein and amyloid deposits in Alzheimer disease. Cold Spring Harb. Perspect. Med. 2:a006262. doi: 10.1101/cshperspect.a006262

Matsumoto, M. L., Wickliffe, K. E., Dong, K. C., Yu, C., Bosanac, I., Bustos, D., et al. (2010). K11-linked polyubiquitination in cell cycle control revealed by a K11 linkage-specific antibody. Mol. Cell 39, 477-484. doi: 10.1016/j.molcel. 2010.07.001

Mercy, L., Hodges, J. R., Dawson, K., Barker, R. A., and Brayne, C. (2008). Incidence of early-onset dementias in Cambridgeshire, United
Kingdom. Neurology 71, 1496-1499. doi: 10.1212/01.wnl.0000334277. 16896.fa

Morishima-Kawashima, M., Hasegawa, M., Takio, K., Suzuki, M., Titani, K., and Ihara, Y. (1993). Ubiquitin is conjugated with amino-terminally processed tau in paired helical filaments. Neuron 10, 1151-1160. doi: 10.1016/08966273(93)90063-w

Morris, M., Maeda, S., Vossel, K., and Mucke, L. (2011). The many faces of tau. Neuron 70, 410-426. doi: 10.1016/j.neuron.2011.04.009

Nagy, E., and Maquat, L. E. (1998). A rule for termination-codon position within intron-containing genes: when nonsense affects RNA abundance. Trends Biochem. Sci. 23, 198-199. doi: 10.1016/s0968-0004(98) 01208-0

Nilsson, P., and Saido, T. C. (2014). Dual roles for autophagy: degradation and secretion of Alzheimer's disease Abeta peptide. Bioessays 36, 570-578. doi: 10. 1002/bies.201400002

Nixon, R. A. (2013). The role of autophagy in neurodegenerative disease. Nat. Med. 19, 983-997. doi: 10.1038/nm.3232

Olsson, A., Höglund, K., Sjögren, M., Andreasen, N., Minthon, L., Lannfelt, L., et al. (2003). Measurement of alpha- and beta-secretase cleaved amyloid precursor protein in cerebrospinal fluid from Alzheimer patients. Exp. Neurol. 183, 74-80. doi: 10.1016/s0014-4886(03)00027-x

Park, Y., Yoon, S. K., and Yoon, J. B. (2009). The HECT domain of TRIP12 ubiquitinates substrates of the ubiquitin fusion degradation pathway. J. Biol. Chem. 284, 1540-1549. doi: 10.1074/jbc.m807554200

Peng, J., Schwartz, D., Elias, J. E., Thoreen, C. C., Cheng, D., Marsischky, G., et al. (2003). A proteomics approach to understanding protein ubiquitination. Nat. Biotechnol. 21, 921-926. doi: 10.1038/nbt849

Pericak-Vance, M. A., Bass, M. P., Yamaoka, L. H., Gaskell, P. C., Scott, W. K., Terwedow, H. A., et al. (1997). Complete genomic screen in late-onset familial Alzheimer disease. Evidence for a new locus on chromosome 12. JAMA 278, 1237-1241. doi: 10.1001/jama.1997.03550150041033

Peth, A., Nathan, J. A., and Goldberg, A. L. (2013). The ATP costs and time required to degrade ubiquitinated proteins by the $26 \mathrm{~S}$ proteasome. J. Biol. Chem. 288, 29215-29222. doi: 10.1074/jbc.m113.482570

Pickart, C. M. (2001). Mechanisms underlying ubiquitination. Annu. Rev. Biochem. 70, 503-533. doi: 10.1146/annurev.biochem.70.1.503

Poulsen, E. G., Steinhauer, C., Lees, M., Lauridsen, A. M., Ellgaard, L., and Hartmann-Petersen, R. (2012). HUWE1 and TRIP12 collaborate in degradation of ubiquitin-fusion proteins and misframed ubiquitin. PLoS One 7:e50548. doi: 10.1371/journal.pone.0050548

Querfurth, H. W., and LaFerla, F. M. (2010). Alzheimer's disease. N. Engl. J. Med. 362, 329-344. doi: 10.1056/NEJMra0909142

Regeur, L., Jensen, G. B., Pakkenberg, H., Evans, S. M., and Pakkenberg, B. (1994). No global neocortical nerve cell loss in brains from patients with senile dementia of Alzheimer's type. Neurobiol. Aging 15, 347-352. doi: 10.1016/01974580(94)90030-2

Reiman, E. M., Quiroz, Y. T., Fleisher, A. S., Chen, K., Velez-Pardo, C., JimenezDel-Rio, M., et al. (2012). Brain imaging and fluid biomarker analysis in young adults at genetic risk for autosomal dominant Alzheimer's disease in the presenilin 1 E280A kindred: a case-control study. Lancet Neurol. 11, 1048-1056. doi: 10.1016/S1474-4422(12)70228-4

Rovelet-Lecrux, A., Hannequin, D., Raux, G., Le Meur, N., Laquerriere, A., Vital, A., et al. (2006). APP locus duplication causes autosomal dominant early-onset Alzheimer disease with cerebral amyloid angiopathy. Nat. Genet. 38, 24-26. doi: $10.1038 /$ ng 1718

Saido, T., and Leissring, M. A. (2012). Proteolytic degradation of amyloid betaprotein. Cold Spring Harb. Perspect. Med. 2:a006379. doi: 10.1101/cshperspect. a006379

Sankaranarayanan, S., Barten, D. M., Vana, L., Devidze, N., Yang, L., Cadelina, G., et al. (2015). Passive immunization with phospho-tau antibodies reduces tau pathology and functional deficits in two distinct mouse tauopathy models. PLoS One 10:e0125614. doi: 10.1371/journal.pone.0125614

Schipanski, A., Oberhauser, F., Neumann, M., Lange, S., Szalay, B., Krasemann, S., et al. (2014). The lectin OS-9 delivers mutant neuroserpin to endoplasmic reticulum associated degradation in familial encephalopathy with neuroserpin inclusion bodies. Neurobiol. Aging 35, 2394-2403. doi: 10 1016/j.neurobiolaging.2014.04.002

Selkoe, D. J. (2001). Alzheimer's disease: genes, proteins and therapy. Physiol. Rev. $81,741-766$. 
Selkoe, D. J., Mandelkow, E., and Holtzman, D. M. (eds). (2012). "The biology of Alzheimer's disease," in A Subject Collection from Cold Spring Harbor Perspectives in Medicine, (New York: Cold Spring Harbor Laboratory Press).

Serrano-Pozo, A., Frosch, M. P., Masliah, E., and Hyman, B. T. (2011). Neuropathological alterations in Alzheimer disease. Cold Spring Harb. Perspect. Med. 1:a006189. doi: 10.1101/cshperspect.a006189

Simic, G., Stanic, G., Mladinov, M., Jovanov-Milosevic, N., Kostovic, I., and Hof, P. R. (2009). Does Alzheimer's disease begin in the brainstem? Neuropathol. Appl. Neurobiol. 35, 532-554. doi: 10.1111/j.1365-2990.2009. 01038.x

Sleegers, K., Brouwers, N., Gijselinck, I., Theuns, J., Goossens, D., Wauters, J., et al. (2006). APP duplication is sufficient to cause early onset Alzheimer's dementia with cerebral amyloid angiopathy. Brain 129, 2977-2983. doi: 10. 1093/brain/awl203

Suh, J., Choi, S. H., Romano, D. M., Gannon, M. A., Lesinski, A. N., Kim, D. Y., et al. (2013). ADAM10 missense mutations potentiate beta-amyloid accumulation by impairing prodomain chaperone function. Neuron 80, 385-401. doi: 10.1016/j.neuron.2013.08.035

Swaab, D. F., Pool, C. W., and van Leeuwen, F. W. (1977). Can specificity ever be proved in immunocytochemical staining? J. Histochem. Cytochem. 25, 388-391. doi: $10.1177 / 25.5 .325124$

Tan, Z., Sun, X., Hou, F. S., Oh, H. W., Hilgenberg, L. G., Hol, E. M., et al. (2007). Mutant ubiquitin found in Alzheimer's disease causes neuritic beading of mitochondria in association with neuronal degeneration. Cell Death Differ. 14, 1721-1732. doi: 10.1038/sj.cdd.4402180

Thrower, J. S., Hoffman, L., Rechsteiner, M., and Pickart, C. M. (2000). Recognition of the polyubiquitin proteolytic signal. EMBO J. 19, 94-102. doi: 10.1093/emboj/19.1.94

Todi, S. V., and Paulson, H. L. (2011). Balancing act: deubiquitinating enzymes in the nervous system. Trends Neurosci. 34, 370-382. doi: 10.1016/j.tins.2011. 05.004

Tsakiri, E. N., and Trougakos, I. P. (2015). The amazing ubiquitin-proteasome system: structural components and implication in aging. Int. Rev. Cell Mol. Biol. 314, 171-237. doi: 10.1016/bs.ircmb.2014.09.002

Tseng, B. P., Green, K. N., Chan, J. L., Blurton-Jones, M., and LaFerla, F. M. (2008). Abeta inhibits the proteasome and enhances amyloid and tau accumulation. Neurobiol. Aging 29, 1607-1618. doi: 10.1016/j.neurobiolaging.2007. 04.014

Tucker, S. M., Borchelt, D. R., and Troncoso, J. C. (2008). Limited clearance of pre-existing amyloid plaques after intracerebral injection of Abeta antibodies in two mouse models of Alzheimer disease. J. Neuropathol. Exp. Neurol. 67, 30-40. doi: 10.1097/nen.0b013e31815f38d2

van Den Hurk, W. H., Willems, H. J., Bloemen, M., and Martens, G. J. (2001). Novel frameshift mutations near short simple repeats. J. Biol. Chem. 276, 11496-11498. doi: 10.1074/jbc.m011040200

van Leeuwen, F. W., De Kleijn, D. P., van Den Hurk, H. H., Neubauer, A., Sonnemans, M. A., Sluijs, J. A., et al. (1998). Frameshift mutants of beta amyloid precursor protein and ubiquitin-B in Alzheimer's and down patients. Science 279, 242-247. doi: 10.1126/science.279.5348.242 van Leeuwen, F. W., Fischer, D. F., Kamel, D., Sluijs, J. A., Sonnemans, M. A., Benne, R., et al. (2000). Molecular misreading: a new type of transcript mutation expressed during aging. Neurobiol. Aging 21, 879-891. doi: 10. 1016/S0197-4580(00)00151-2

van Leeuwen, F. W., van Tijn, P., Sonnemans, M. A., Hobo, B., Mann, D. M., van Broeckhoven, C., et al. (2006). Frameshift proteins in autosomal dominant forms of Alzheimer disease and other tauopathies. Neurology 66, S86-S92. doi: 10.1212/01.wnl.0000193882.46003.6d

van Tijn, P., Dennissen, F. J., Gentier, R. J., Hobo, B., Hermes, D., Steinbusch, H. W., et al. (2012). Mutant ubiquitin decreases amyloid beta plaque formation in a transgenic mouse model of Alzheimer's disease. Neurochem. Int. 61, 739-748. doi: 10.1016/j.neuint.2012.07.007

van Tijn, P., De Vrij, F. M., Schuurman, K. G., Dantuma, N. P., Fischer, D. F., van Leeuwen, F. W., et al. (2007). Dose-dependent inhibition of proteasome activity by a mutant ubiquitin associated with neurodegenerative disease. J. Cell Sci. 120, 1615-1623. doi: 10.1242/jcs.03438

Verhoef, L. G., Heinen, C., Selivanova, A., Halff, E. F., Salomons, F. A., and Dantuma, N. P. (2009). Minimal length requirement for proteasomal degradation of ubiquitin-dependent substrates. FASEB J. 23, 123-133. doi: 10 1096/fj.08-115055

Vogel, G. (1998). Possible new cause of Alzheimer's disease found. Science 279:174 doi: 10.1126/science.279.5348.174

Wang, I. X., Core, L. J., Kwak, H., Brady, L., Bruzel, A., McDaniel, L., et al. (2014). RNA-DNA differences are generated in human cells within seconds after RNA exits polymerase II. Cell Rep. 6, 906-915. doi: 10.1016/j.celrep.2014.01.037

Weksler, M. E., Szabo, P., Relkin, N. R., Reidenberg, M. M., Weksler, B. B., and Coppus, A. M. (2013). Alzheimer's disease and Down's syndrome: treating two paths to dementia. Autoimmun. Rev. 12, 670-673. doi: 10.1016/j.autrev.2012. 10.013

West, M. J., Coleman, P. D., Flood, D. G., and Troncoso, J. C. (1994). Differences in the pattern of hippocampal neuronal loss in normal ageing and Alzheimer's disease. Lancet 344, 769-772. doi: 10.1016/s0140-6736(94)92338-8

Wolf, D. H., and Hilt, W. (2004). The proteasome: a proteolytic nanomachine of cell regulation and waste disposal. Biochim. Biophys. Acta 1695, 19-31. doi: 10. 1016/j.bbamcr.2004.10.007

Zouambia, M., Fischer, D. F., Hobo, B., De Vos, R. A., Hol, E. M., Varndell, I. M., et al. (2008). Proteasome subunit proteins and neuropathology in tauopathies and synucleinopathies: consequences for proteomic analyses. Proteomics 8, 1221-1236. doi: 10.1002/pmic.200700679

Conflict of Interest Statement: The authors declare that the research was conducted in the absence of any commercial or financial relationships that could be construed as a potential conflict of interest.

Copyright (C) 2015 Gentier and van Leeuwen. This is an open-access article distributed under the terms of the Creative Commons Attribution License (CC BY). The use, distribution and reproduction in other forums is permitted, provided the original author(s) or licensor are credited and that the original publication in this journal is cited, in accordance with accepted academic practice. No use, distribution or reproduction is permitted which does not comply with these terms. 